ORIGINAL ARTICLE

\title{
Prelacteal Feeding Practices among Mothers in Motta Town, Northwest Ethiopia: A Cross-sectional Study
}

\section{Tilahun Tewabe ${ }^{1 *}$}

\section{OPEN ACCESS}

Citation: Tilahun Tewabe. Prelacteal Feeding Practices among Mothers in Motta Town, East Gojjam Zone, Amhara Regional State, Ethiopia, 2015: A Crosssectional Study. Ethiop J Health Sci.2017; 28 (4):393

doi:http://dx.doi.org/10.4314/ejhs.v28i4.5

Received: January 31, 2018

Accepted: February 6, 2018

Published: July 1, 2018

Copyright: (C) 2018 Tilahun Tewabe.

This is an open access article distributed under the terms of the Creative Commons Attribution License, which permits unrestricted use, distribution, and reproduction in any medium, provided the original author and source are credited.

Funding: Addis Ababa University

Competing Interests: The authors declare that this manuscript was approved by all authors in its form and that no competing interest exists.

Affiliation and Correspondence:

${ }^{1}$ Peaditrics and Childe Health Nursing,

Bahir Dar Univesity, Ethiopia

*Email: tilahun.tewabe01@gmail.com

\section{ABSTRACT}

BACKGROUND: Optimal breastfeeding is recommended up to two years, i.e, it prevents 1.4 million child deaths per year. Despite this prelacteal feeding is commonly practiced in Ethiopia due to different reasons. The objective of this study was to assess prelacteal feeding and associated factors among mothers who have infants less than six months of age.

METHOD: A community based quantitative cross sectional study was conducted from April 7, 2015 to May 7, 2015. Using simple random sampling method total of 423 mothers with infant less than six months old were included in this study. The data were collected by using an interviewer admini stered questionnaire. Both simple and multiple logistic regression analyses were computed to identify factors associated with prelacteal feeding.

RESULTS: Prevalence of prelacteal feeding was 20.3\% [95\% CL: $16.38 \%-24.02 \%$ ]. The most common prelacteal feeding in the study area was butter (62.2\%). Mothers with young infant who fed colostrum [AOR=3.540 (1.534, 8.173), initiated breastfeeding on time [AOR $=4.4832(1.823,11.028)]$ and supported by husband's [AOR=2.686 (1.037, 6.953)] were less likely to practice prelacteal feeding to their infant than their counterparts.

CONCLUSIONS: Prelacteal feeding was common in the study area. Colostrum feeding, timely initiations of breastfeeding and husband support were the independent predictors of prelacteal feeding practices. Recommendation to avoid prelacteal feeding practices were: increasing the habit of mothers to initiate breastfeeding timely and to feed colostrum through education, empowering husbands regarding to breastfeeding and avoiding traditional practices that hinder optimal breastfeeding like colostrum avoidance. KEYWORDS: Prelacteal feeding, Prevalence, Associated Factors, Motta, Ethiopia. 


\section{INTRODUCTION}

Breast milk provides all infants nutritional and fluid needs in the first six months and is a perfect combination of proteins, fats, carbohydrate $\mathrm{s}$ and fluids and it is the best and cost effective intervention to reduce infant morbidities and mortalities. The beneficial effect of breastfeeding depends on appropriate breastfeeding practices like timely initiation, colostrums feeding and avoidance of prelacteal feeding (1).

Breastfed babies got fewer infections; i.e., less diarrhea and vomiting, chest and ear infections and less risk of chronic diseases in later life since breast milk makes a baby's immune system work best $(1,2)$. Optimal breastfeeding is recommended; i.e. timely initiation of breastfeeding, colostrum feeding, exclusively breastfed for the first six months and continuation of breastfeeding up 24 months or beyond $(2,3)$.

Early supplementation,i.e., prelacteal feeding (the administration of any foods or liquids other than breast milk to an infant) is discouraged for several reasons: it exposes infants to pathogens and increases their risk of infection, decreases infant's intake of breast milk and therefore suckling, and supplementary food is often nutritionally inferior (2).

Suboptimal breastfeeding contributes $45 \%$ of neonatal infectious deaths, $30 \%$ of

diarrheal deaths and $18 \%$ of acute respiratory deaths among under five children in developing countries and it increases the risk of other diseases like: diabetes, obesity, autoimmune disorders and cardiovascular diseases (2). In Ethiopia suboptimal breastfeeding contributes to 70,000 infant deaths per year, i.e., $24 \%$ of the total infant death annually (4). Worldwide optimal breastfeeding has the potential to prevent 1.4 million under five deaths per year (5).

Data from the Ethiopian Demographic and Health Survey (EDHS) showed that 27\% of children were given prelacteal feeds within the first three days of life and is more commonly practiced in rural areas than in urban areas (6). The Ethiopian infant and young child feeding guideline discourages prelacteal feeding practices and promotes exclusive breastfeeding practice up to six months (7).
Breastfeeding is a means for achieving the sustainable development goals (SDG) related to children, particularly for goal 2.2 by 2030 end all forms of malnutrition and to achieve the 2025 internationally agreed targets on stunting and wasting in children under five years of age (8).

Therefore, the purpose of this study was to assess prelacteal feeding practices and associated factors among mothers of children less than 6 months old in Motta town, East Gojjam zone, Ethiopia.

\section{METHODS}

Study setting and participants: A community based quantitative cross-sectional study was conducted from April 7 to May 7, 2015. The study was conducted in Motta town which is located in the Amhara National, Regional State, East Gojjam Zone, Ethiopia. It is $371 \mathrm{~km}$ away from Addis Ababa. Motta town was founded in 1754. The town has 4 kebeles (part of the town divided for administrative purposes). By the year 2015 the total population of the town was 33,500, out of them 520 were children less than 6 months of age. The town has 17 governmental and nongovernmental health care institutions. These are 1 hospital, 1 health center, 5 clinics and 1 pharmacy and 9 drug stores (9).

The sample size was calculated using single population proportion formula by considering the following assumptions; $\mathrm{P}$ (proportion of prelacteal feeding practices among mothers) $=50 \%$, the level of confidence $95 \%$, margin of error $(\mathrm{d})=5 \%$ and $10 \%$ non- response rate. Using a simple random sampling technique, 423 mothers were participating in the study. To select study participants from each kebele: the sample size was proportionally allocated to size and a lottery method was used to select each study participant. The actual age of the child was determined during data collection period and by reviewing birth cards.

Measurement: A structured interviewer administered questionnaire was used to collect data from participants or mothers of a child. The questionnaire was constructed by adopting from Ethiopia Demographic and Health Survey (EDHS) 2011 (6) and from previous research done on a similar topic and modified accordingly (10) and

DOI: http://dx.doi.org/10.4314/ejhs.v28i4.5 
knowledge questions were adapted from related topics done on breastfeeding (11).

Four diploma nurses were recruited as data collectors and two Bachelors of Science nurses were recruited as supervisors. All data collectors and supervisors attended a one day training course on the study protocol and interviewing skills.

Variables of the study: The dependent variable of this study was prelacteal feeding practice while the independent variables were; maternal related: age, ethnicity, religion, marital status, educational status, occupation, mother's knowledge on breastfeeding, exposure to information about breastfeeding, maternal illness; obstetric and health service related: parity, antenatal care, breastfeeding counseling during pregnancy, place of delivery, mode of delivery, postnatal care; infant related: sex, birth order, birth interval, timely initiation of breastfeeding, colostrum feeding status, infant health; family and sociocultural related factors:husband occupation, husband educational status, husband support, income, type of family, cultural support, organizational support, and religious father support.

\section{Operational definitions}

Prelacteal feeding practice: If an infant within the first three days of life feed something other than breast milk $(6,10,11)$.

Timely initiation of breastfeeding: If an infant within one hour (including one hour) of birth is put on mother's breast to feed $(6,11)$.

Adequate knowledge about breastfeeding: If a mother answered four questions out of seven on breastfeeding knowledge correctly.

Husband's support: If a mother is supported by husband either by advice or economy to breastfed an infant.

Statistical Analysis: The collected data were checked manually for completeness and consistencies, and then it was coded and entered in EPI Info version 3.5.3 and exported to SPSS version 16 for analysis. Descriptive statistics were used to summarize the sociodemographic characteristics' of the study participants and the prevalence of prelacteal feeding.To identify factors associated with prelacteal feeding practice, binary logistic regression analysis carried out, first bivariate logistic regression was performed to each independent variable with the dependent variable and those variables with a $\mathrm{p}$ value $<0.05$ was included in the final multivariate analysis. Strength of association was measured using odds ratio and $95 \%$ confidence intervals. Statistical significance was declared at $\mathrm{P}$ value $<0.05$.

Ethics approval and consent to participate: Ethical clearance was obtained from AAU, department of nursing and midwifery research committee. Each study participant was adequately informed about the objective of the study and anticipated benefits and risk of the study by their data collector. Verbal consent was obtained from study participants for protecting autonomy and ensuring confidentiality. Respondents were also told the right not to respond to the questions if they didn't want to respond or to terminate the interview at any time.

\section{RESULTS}

Socio-demographic characteristics: Out of 423 eligible mothers, 404 mothers participated in this study, which made a response rate of $95.5 \%$. Most (88.6\%) of mothers were between 20-34 years. With regard to level education of mothers, 163 $(40.2 \%)$ have not got any form of formal education. Half $(50.2 \%)$ of mothers were housewifes. Above half, 249 (61.6\%) of respondents household income was less than 1500 Ethiopian Birr (55USD) (Table 1).

DOI: http://dx.doi.org/10.4314/ejhs.v28i4.5 
Table 1: Socio-demographic characteristics mothers (respondents) who have infants less than six months old, in Motta town, East Gojjam Zone, Ethiopia, 2015 ( $n=404)$

\begin{tabular}{|c|c|c|c|}
\hline Variable & Category $(\mathrm{n}=404)$ & Frequency & Percent \\
\hline \multirow[t]{3}{*}{ Age of mother( in years) } & $15-19$ & 5 & $1.2 \%$ \\
\hline & $25-34$ & 358 & $88.6 \%$ \\
\hline & 35 and above & 41 & $10.1 \%$ \\
\hline \multirow[t]{4}{*}{ Religion } & Orthodox & 229 & $56.7 \%$ \\
\hline & Muslim & 157 & $38.9 \%$ \\
\hline & Protestant & 12 & $3 \%$ \\
\hline & Others $^{\mathrm{a}}$ & 6 & $1.5 \%$ \\
\hline \multirow{4}{*}{$\begin{array}{l}\text { Level of education of } \\
\text { mother }\end{array}$} & No education & 221 & $54.7 \%$ \\
\hline & Primary education & 61 & 15.1 \\
\hline & Secondary education & 42 & 10.4 \\
\hline & Diploma/degree & 80 & $19.9 \%$ \\
\hline \multirow{3}{*}{$\begin{array}{l}\text { Occupational status of } \\
\text { mother }\end{array}$} & Housewife & 203 & $50.2 \%$ \\
\hline & Employed & 81 & 20.1 \\
\hline & Unemployed & 120 & $29.7 \%$ \\
\hline \multirow{3}{*}{ Current marital status } & Single & 20 & $5 \%$ \\
\hline & Married & 347 & $85.9 \%$ \\
\hline & Unmarried $^{\mathrm{c}}$ & 37 & $9.3 \%$ \\
\hline \multirow{4}{*}{$\begin{array}{l}\text { Husband educational level } \\
(\mathrm{n}=353)\end{array}$} & No education & 155 & $44.5 \%$ \\
\hline & Primary education & 53 & $15 \%$ \\
\hline & Secondary education & 42 & $11.9 \%$ \\
\hline & Diploma/degree & 101 & $28.6 \%$ \\
\hline \multirow{4}{*}{ Husband occupation } & Government Employed & 91 & $25.8 \%$ \\
\hline & Private Employed & 20 & $5.7 \%$ \\
\hline & Merchant & 81 & $22.9 \%$ \\
\hline & Others & 161 & $45.6 \%$ \\
\hline Household income (with & $<1500^{\mathrm{d}}$ & 249 & $61.6 \%$ \\
\hline Ethiopian birr) & $>1500$ & 155 & $38.4 \%$ \\
\hline
\end{tabular}

Infant, maternal and prelacteal feeding practices related characteristics: Most (72\%) of infants second and above in birth order. One hundred fifteen $(28.5 \%)$ infants were between 31 90 days of age. The majority $(86.1 \%)$ and nearly half $(48.8 \%)$ of mothers received antenatal and postnatal care, respectively. And out of them $206(59.2 \%)$ were counseled for breast feeding.

The majority $(79.7 \%)$ of mothers didn't give prelacteal food other than breast milk within three days of an infant life. Prevalence of prelacteal feeding practice was $20.3 \%$ [95\% CL: $16.38 \%$ $24.02 \%)$. The most common prelacteal feedings were: butter $(62.2 \%)$, cow milk $(18.3 \%)$ and water $(14.6 \%)$. Among mothers who gave prelacteal feed to their infant, the main reasons mentioned were: culture/tradition $(42.2 \%)$, illness of the mother $(16.9 \%)$, sore nipples $(16.9 \%)$, illness of a child $(15.7 \%)$ and milk was not coming out of the breast. Most mothers $(62.7 \%)$ gave prelacteal feeding to their children of their own decision (Table 2).

DOI: http://dx.doi.org/10.4314/ejhs.v28i4.5 
Table 2: Infant, maternal and prelacteal feeding related practices characteristics of study participants in Motta town, East Gojjam zone, Ethiopia, $2015(\mathrm{n}=404)$

\begin{tabular}{|c|c|c|c|}
\hline Variable & Response $(n=423)$ & Frequency & Percent (\%) \\
\hline \multirow[t]{2}{*}{ Sex of child } & Male & 180 & $44.6 \%$ \\
\hline & Female & 224 & $55.4 \%$ \\
\hline \multirow[t]{3}{*}{ Age of child } & $0-30$ days & 50 & $12.4 \%$ \\
\hline & 31-90 days & 115 & $28.5 \%$ \\
\hline & 90-180 days & 239 & $59.1 \%$ \\
\hline \multirow[t]{2}{*}{ Birth order } & First & 109 & $27 \%$ \\
\hline & Second and above & 295 & $72 \%$ \\
\hline \multirow[t]{2}{*}{ ANC follow up } & Yes & 348 & $86.1 \%$ \\
\hline & No & 56 & $13.9 \%$ \\
\hline \multirow{2}{*}{$\begin{array}{l}\text { Counseling related breast feeding during ANC } \\
(\mathrm{n}=348)\end{array}$} & Yes & 206 & $59.2 \%$ \\
\hline & No & 142 & $41.8 \%$ \\
\hline \multirow[t]{3}{*}{ Place of birth } & Hospital & 270 & $66.8 \%$ \\
\hline & Health center/clinic/ & 67 & $16.6 \%$ \\
\hline & Home & 67 & $16.6 \%$ \\
\hline \multirow[t]{2}{*}{ Mode of delivery } & Vaginal /normal & 366 & $90.6 \%$ \\
\hline & Caesarean section & 38 & $9.4 \%$ \\
\hline \multirow[t]{2}{*}{ PNC } & Yes & 197 & $48.8 \%$ \\
\hline & No & 207 & $51.2 \%$ \\
\hline \multirow[t]{2}{*}{ Timely initiation of breastfeeding } & Yes & 318 & $78.7 \%$ \\
\hline & No & 86 & $21.3 \%$ \\
\hline \multirow[t]{2}{*}{ Colostrum feeding } & Yes & 322 & $79.7 \%$ \\
\hline & No & 82 & $20.3 \%$ \\
\hline \multirow[t]{2}{*}{ Prelacteal feeding } & No & 322 & $79.7 \%$ \\
\hline & Yes & 82 & $20.3 \%$ \\
\hline \multirow{5}{*}{$\begin{array}{l}\text { Type of food you give( within three days of infant } \\
\text { life) }\end{array}$} & Water & 12 & $14.6 \%$ \\
\hline & Butter & 51 & $62.2 \%$ \\
\hline & Cow milk & 15 & $18.3 \%$ \\
\hline & Sugar solution & 3 & $3.7 \%$ \\
\hline & Honey & 1 & $1.2 \%$ \\
\hline \multirow[t]{5}{*}{ Why you give other feeding to your infant } & Culture /tradition & 35 & $42.2 \%$ \\
\hline & Maternal illness & 14 & $16.9 \%$ \\
\hline & Sore nipples & 14 & $16.9 \%$ \\
\hline & Infant illness & 13 & $15.7 \%$ \\
\hline & Delayed milk secretion & 7 & $8.4 \%$ \\
\hline \multirow[t]{4}{*}{ Who influence you to give other feeding $(n=202)$} & My own decision & 52 & $62.7 \%$ \\
\hline & Grand parents & 17 & $20.5 \%$ \\
\hline & My friends & 10 & $12 \%$ \\
\hline & Others & 4 & $4.8 \%$ \\
\hline \multirow[t]{2}{*}{ Does your husband support breastfeeding } & Yes & 310 & $87.8 \%$ \\
\hline & No & 43 & $12.2 \%$ \\
\hline
\end{tabular}

DOI: http://dx.doi.org/10.4314/ejhs.v28i4.5 
Knowledge of mothers regarding to breastfeeding: More than half $(57.7 \%)$ of mothers know about as there is no need to give prelacteal feeding infant without breast milk and $76.5 \%$ mothers had adequate knowledge regarding to optimal breastfeeding practice (Table 3 ).

Table 3: Breastfeeding knowledge of mothers who have infants less than six months old in Motta town, East Gojjam Zone, Ethiopia, 2015 ( $\mathrm{n}=404)$

\begin{tabular}{llll}
\hline Knowledge questions & Responses & Frequency & percent \\
\hline Breastfeeding is important for infant health? & Yes & 389 & 96.3 \\
& No & 15 & 3.7 \\
Breastfeeding is important for maternal health? & Yes & 215 & 53.2 \\
& No & 189 & 46.8 \\
An infant should be put to breast immediately after & Yes & 282 & 69.8 \\
birth? & No & 122 & 30.2 \\
The first milk/colostrum should be given to an infant? & Yes & 272 & 67.3 \\
& No & 132 & 32.7 \\
Pre-lacteal feeding is needed for an infant before & Yes & 171 & 42.3 \\
starting breast milk? & No & 233 & 57.7 \\
Breast milk alone without water and other liquids is & Yes & 268 & 66.3 \\
enough for an infant during the first 6 months of life? & No & 136 & 33.7 \\
Starting from 6 month an infant should start & Yes & 253 & 62.6 \\
complementary feeding and continued breastfeeding & No & 151 & 37.4 \\
up to 2 years and beyond? & & &
\end{tabular}

Factors associated with prelacatal feeding: From total participants of this study, 20.3\% [95\%CL: $16.38 \%-24.02 \%$ ) of mothers gave prelacteal feeding to the newborn within three days. To identify factors associated with prelacteal feeding practices, each variable were assessed independently whether they were predicting of prelacteal feeding practices or not. First variables were tested using bivariate analysis. Variables which were associated in with the bivariate logistic regression analysis $(\mathrm{P}<0.05)$ were: age of the mother, educational status of mother, husband educational status, an order of the child, antenatal care, breastfeeding counseling during ANC, place of birth, mode of delivery, postnatal care, timely initiation of breastfeeding, colostrum feeding, information about breastfeeding and husband support. Variables which were associated in the bivariate analysis were tested in the final multivariate analysis to see their significant association with prelacteal feeding practices.
After adjusting for potential con founders in multivariate logistic regression analysis: colostrum feeding, timely initiation of breastfeeding and husband support were remained significant. Colostrum feeding was significantly associated with the prelacteal feeding practice. Mothers who didn't fed colostrum to their infant were 3.6 times higher to practice prelacteal feeding than those mothers who fed it $[\mathrm{AOR}=$ $3.540(1.534,8.173)]$.

Timely initiation of breastfeeding was also associated with prelacteal feeding practices. Mothers who initiate breastfeeding within one hour of birth of infant were almost 4 times higher for not giving prelacteal feeding than those mothers who delay initiation of breastfeeding $[\mathrm{AOR}=4.492(2.120,9.517)]$.

Pertaining to support, mothers who got husband support of breastfeeding were almost 3 times more likely not feed prelacteal feeding to the newborn than mothers who were not supported by their husband $[\mathrm{AOR}=3.781(1.568,9.120)]$ (Table 4).

DOI: http://dx.doi.org/10.4314/ejhs.v28i4.5 
Table 4: Factors that affect prelacteal feeding among mothers of infants age less than 6 months using bivariate and multivariate logistic regression analysis model, East Gojjam, Ethiopia, 2015

\begin{tabular}{|c|c|c|c|c|c|}
\hline \multirow[t]{2}{*}{ Variables } & & \multicolumn{4}{|c|}{ Prelacteal feeding } \\
\hline & & $\begin{array}{l}\text { Yes } \\
(\mathrm{N} \& \%)\end{array}$ & $\begin{array}{l}\text { No } \\
(\mathrm{N} \& \%)\end{array}$ & COR (95\% CL) & $\operatorname{AOR}(95 \% \mathrm{CL})$ \\
\hline \multirow[t]{3}{*}{ Age(mother) } & $15-19$ & $0(0)$ & $5(100)$ & & \\
\hline & $20-35$ & $66(18.4)$ & $292(81.6)$ & $2.832(1.432,5.600)$ & \\
\hline & $36+$ & $16(39)$ & $25(61)$ & 1 & \\
\hline \multirow[t]{2}{*}{ Order of child } & First & $14(12.8 \%)$ & $95(87.2 \%)$ & $2.033(1.090,3.790)$ & \\
\hline & $\begin{array}{l}\text { Second and } \\
\text { above }\end{array}$ & $68(23.1 \%)$ & $227(76.9 \%)$ & 1 & \\
\hline \multirow{4}{*}{$\begin{array}{l}\text { Mother } \\
\text { education } \\
\text { Husband } \\
\text { education }\end{array}$} & Uneducated & $66(23.4)$ & $216(76.6)$ & 1 & \\
\hline & Educated & $16(13.1)$ & $106(86.9)$ & $2.024(1.118,3.665)$ & \\
\hline & Uneducated & $53(25.2)$ & $157(74.8)$ & 1 & \\
\hline & Educated & $16(11.2)$ & $127(88.8)$ & $2.680(1.462,4.912)$ & \\
\hline \multirow[t]{2}{*}{ ANC } & yes & $58(16.7 \%)$ & $290(83.3)$ & 1 & \\
\hline & no & $24(42.9)$ & $32(57.1)$ & $3.750(2.059,6.382)$ & \\
\hline \multirow{2}{*}{$\begin{array}{l}\text { Breastfeeding } \\
\text { counseling } \\
\text { during ANC }\end{array}$} & yes & $24(11.7)$ & $182(88.3)$ & 1 & \\
\hline & no & $34(23.9)$ & $108(76.1)$ & $2.387(1.344,4.239)$ & \\
\hline \multirow[t]{2}{*}{ Place of birth } & $\begin{array}{l}\text { Health } \\
\text { facility }\end{array}$ & $51(15.1)$ & $286(84.9)$ & 1 & \\
\hline & Home & $31(46.3)$ & $36(53.7)$ & $4.829(2.744,8.497)$ & \\
\hline \multirow[t]{2}{*}{$\mathrm{PNC}$} & yes & $29(14.7)$ & $168(85.3)$ & 1 & \\
\hline & No & $53(25.6)$ & $154(74.4)$ & $1.994(1.206,3.296)$ & \\
\hline \multirow{2}{*}{$\begin{array}{l}\text { Information } \\
\text { breastfeeding }\end{array}$} & Yes & $68(18.8)$ & $293(81.2)$ & 1 & \\
\hline & No & $14(32.6)$ & $29(67.4)$ & $2.080(1.043,4.148)$ & \\
\hline \multirow{6}{*}{$\begin{array}{l}\text { Timely } \\
\text { initiation } \\
\text { Colostrum } \\
\text { feeding } \\
\text { Husband } \\
\text { support } \\
\end{array}$} & yes & $42(13.2)$ & $276(86.8)$ & 1 & 1 \\
\hline & No & $40(46.5)$ & $46(53.5)$ & $5.714(3.351,9.745)$ & $4.492(2.120,9.517)^{*}$ \\
\hline & yes & $46(14.3)$ & $276(85.7)$ & 1 & 1 \\
\hline & No & $36(43.9)$ & $46(56.1)$ & $4.696(2.746,8.028)$ & $3.540(1.534,8.173) *$ \\
\hline & Yes & $50(16.1)$ & $260(83.9)$ & 1 & \\
\hline & No & $19(44.2)$ & $24(53.8)$ & $4.117(2.099,8.075)$ & $3.781(1.568,9.120)^{*}$ \\
\hline \multicolumn{4}{|l|}{$1=$ reference } & $\mathrm{N}=$ number $\quad \%=$ percent & \\
\hline \multicolumn{4}{|c|}{$\begin{array}{l}\text { In spite what is known about the benefit breastfeed } \\
\text { ing; a significant proportion of mothers practiced } \\
\text { prelacteal feeding in the study area. About } 20.2 \% \\
\text { [95\%CL: } 16.38 \%-24.02 \% \text { ] of mothers reported as } \\
\text { they gave other food to the infant before three } \\
\text { days of infant life. This result is comparable to the } \\
2011 \text { Ethiopian DHS report } 27 \% \text { (6) and other } \\
\text { studies done in: Nepal } 26.5 \% \text { (12), Benchmaji }\end{array}$} & \multicolumn{2}{|c|}{$\begin{array}{l}\text { zone Ethiopia } 21.9 \%(13) \text {, Honduras } 19.1 \%(14) \text {, } \\
\text { Ghana } 18 \% \text { and it is slightly higher than } \\
\text { prevalence of prelacteal feeding practices in } \\
\text { Nigeria } 11.7 \% \text { (15) and Jimma Ethiopia } 12.5 \% \\
\text { (16). The result of this study is lower than other } \\
\text { studies done in: Raya Kobo } 38.8 \% \text { (10), Harar, } \\
\text { Ethiopia } 45.4 \% \text { (17), India } 40.2 \%(18) \text {, Maharasht } \\
\text { ra, India, } 42.7 \% \text { (19), Egypt } 58 \%(20) \text {, in a study } \\
\text { done Safdarjung Hospital } 78 \% \text { (21), Gonder } 79 \% \\
\text { (22). The difference might be due to methodologic }\end{array}$} \\
\hline
\end{tabular}

DOI: http://dx.doi.org/10.4314/ejhs.v28i4.5 
al variations between studies, dissimilarities in infant and maternal sociodemographic characterist ics and health and health service utilization characteristics between respondents of the referenced areas and the study place.

The most common prelacteal feedings practiced in the study area were: butter $(62.2 \%)$, cow milk $(18.3 \%)$ and water $(14.6 \%)$ which were similar with other country practices like in: Egypt (20), Benchi-maji zone Ethiopia (13), Nepal (12), Nigeria(15) and in Raya Kobo Ethiopia (10). This may be due to false perception of mothers for these feeding which should be discouraged i.e., important for infant development and water relieve infant thristy .

Mothers who did not feed colostrum were more likely not to give prelacteal feeds. This finding is consistent with findings in Gonder Ethiopia (23) while mothers didn't initiate breastfeeding within one hour of birth were almost 4 times to practice prelacteal feeding than who initiate within one hour of birth, which is in line with the study findings in Raya Kobo (10) and Harar Ethiopia (17). This might be due to the fact that when mother delays initiation breast milk infants suckling activity decreases and which in turn affects or decreases maternal milk secretion due to decreased breast stimulation. Which finally made the mother to give other food to the infant, the reverse is true for colostrum feeding. The explanations given in this study were: culture/ tradition like giving liquid will clean the baby's throat, illness of the mother, sore nipples, and illness of child and milk was not coming out. This habit harms the newborn and exposes him/her to various morbidities and therefore, the practice needs to be discouraged.

Even if most mothers started prelacteal feeding by their own decision, husband support had a significant relationship with prelacteal feeding practice in the study area. Mothers who were not supported by the husband were almost 4 times higher to give prelacteal feeding than mothers who were supported. Though no available evidence as husband support affects prelacteal feeding it was mentioned as husband support affects breastfeeding practices in studies done in Malaysia (24), and Awi Zone Ethiopia (25). This might be in Ethiopia the husbands plays a major role in decision making about family and household matters and in some families they are the bread winners for the household. The power which husbands have traditionally held affects intra-house-hold activities and many aspects of family life including infant feeding practices.

A limitation this study was that it assessed only the quantitative aspects of prelacteal feeding practices and this may underestimate the prevalence of prelacteal feeding practices in the study area due to recall bias.

The prevalence of prelaceal feeding practices in the study area was significantly higher. Among diferrent socio demographic, health sevice, maternal, and infant related factors studied: colostrum feeding, timely initiation of breastfeeding and husband support were determinant factors for prelacteal feeding practices in the study area. Recommendations for decreasing prelacteal feeding practices include: behavior change communication to avoid traditional activities like colostrum avoidance and early initiation of prelacteal feeding, increasing professional habit of educating mothers regarding infant feeding practices and every arrangement should be made to increase timely initiation of breastfeeding and colostrum feeding, community based breastfeeding education and empowering husbands regarding to breastfeed should be given.

\section{ACKNOWLEDGEMENT}

The author would like to thank librarian staffs, study participants, data collectors and supervisors for their cooperation during the entire work.

DOI: http://dx.doi.org/10.4314/ejhs.v28i4.5 


\section{REFERNCES}

1. UNICEF. Tracking Progress on Child and Maternal Nutrition:A Survival and Development Priority. New York:UNICEF;2009.

2. WHO. Mortality and burden of disease attributable to selected major risks. Geneva: WHO; 2009.

3. 3. WHO (World Health Organization):Infant and young child nutrition:situation analysis and prospects inthe African region.AFR/RC51/11 Rev 2001,1:18.

4. Ethiopian Federal Ministry of Health. National Strategy for child survival. Addis Ababa,Ethiopia;2015.

5. Black RE, Allen LH, Bhutta ZA, Caulfield LE, De Onis M, Ezzati M, et al. Maternal and child undernutrition: global and regional exposures and health consequences. The lancet. 2008;371(9608):243-60.

6. Central Statistical Agency. Ethiopia Demographic and Health Survey 2011 A.A, Ethiopia: ICF International, Calverton, Maryland, USA; March 2012.

7. Federal Ministry of Health, Family Health Department of Ethiopia. National Strategy on Infant and Young Child Feeding. Addis Ababa,Ethiopia;2004.

8. Buse K, Hawkes S. Health in the sustainable development goals: ready for a paradigm shift? Globalization and health. 2015;11(1):1.

9. Motta town administration. Health office report. Motta;2015.

10. Legesse M, Demena M, Mesfin F, Haile D. Prelacteal feeding practices and associated factors among mothers of children aged less than 24 months in Raya Kobo district, North Eastern Ethiopia: a cross-sectional study. International breastfeeding journal. 2014;9(1):189.

11. Mekuria G, Endris M. Exclusive breastfeeding and associated factors among mothers in Debre Markos, Northwest Ethiopia. International Breastfeeding Journal 2015;10:1.

12. Khanal V, Adhikari M, Sauer K, Zhao Y, Egata G, Berhane Y, et al. Factors associated with the introduction of prelacteal feeds in Nepal: findings from the Nepal demographic and health survey 2011. Int Breastfeed J. 2013;8(1):9.

13. Muluken A. Assessement of Prevalence of Prelactal Feeding and Associated Factors among Mothers of Children less than one year of Age in Mizan-Aman Town Benchmaji Zone, South West Ethiopia: AAU; 2015.

14. SEGÃœRA-MILLÃ •NRPS,CANAHÃœATIJ , ALLEN H. Prelacteal Feeds Are Negatively Associated with Breast-Feeding Outcomes in Honduras. Journal of Nutrition. 2005; 126: 2765-2773.

15. 1Ibadin O, Ofili N, Monday $\mathrm{P}$, Nwajei C. Prelacteal feeding practices among lactating mothers in Benin City, Nigeria. Nigerian Journal of Paediatrics. 2013;40(2):139-44.

16. Tamiru D, Belachew T, Loha E, Mohammed S. Sub-optimal breastfeeding of infants during the first six months and associated factors in rural communities of Jimma Arjo Woreda, Southwest Ethiopia. BMC Public Health. 2012;12(1):363.

17. Yosef B, Mengistie B, Mesfine F. Prelacteal Feeding Practice and Associated Factors among Mothers Attending Immunization Clinic in Harare Region Public Health Facilities, Eastern Ethiopia. Open Journal of Preventive Medicine. 2014;4:529-534. http://dx.doi.org/10.4236/ojpm.2014.47063.

18. Wadde SK, Yadav VB. Prelacteal feeding practices in a rural community. Indian Medical Gazette. 2011;145(9):337-4.

19. Dawal S, Inamdar I, Saleem T, Priyanka S, Doinale M. Study of Pre Lacteal Feeding Practices and its Determinants in a Rural Area of Maharashtra. Sch J App Med Sci. 2014;2(4D):1422-7.

20. El-Gilany A-H, Abdel-Hady DM. Newborn first feed and prelacteal feeds in Mansoura, Egypt. BioMed research international. 2014;2014.

21. Saxena ${ }^{1}$ P. Contemporary breast feeding practices-A hospital based study. Indian J Prev Soc Med. 2006;37(3\&):4.

22. Getahun Z,Tafesse Y,Teshome B, Scherbaum $\mathrm{V}$. The state of exclusive breast feeding

DOI: http://dx.doi.org/10.4314/ejhs.v28i4.5 
and complementary feeding practice in selected Amhara and Tigray in Ethiopia. In collaboration of Ethiopia health and nutrition, 2003.

23. Rogers NL, Abdi J, Moore D, Nd'iangui S, Smith LJ, Carlson AJ, et al. Colostrum avoidance, prelacteal feeding and late breastfeeding initiation in rural Northern Ethiopia. Public health nutrition. 2011;14(11):2029-36.

24. Taddele M, Abebe L, Fentahun N. Exclusive Breastfeeding and Maternal Employment in Ethiopia. A Comparative Cross- Sectional Study. International Journal of Nutrition and Food Sciences. 2014;3(6):497-503.

25. Tan KL. Factors associated with exclusive breastfeeding among infants under six months of age in peninsular,Malaysia. International Breastfeeding Journal. 2011;6(1):2.

DOI: http://dx.doi.org/10.4314/ejhs.v28i4.5 